\title{
In Appreciation for a Job Well Done!
}

\author{
Howard E. Gendelman ${ }^{1} \cdot$ Robin Taylor ${ }^{1}$ \\ Published online: 8 February 2019 \\ (C) Springer Science+Business Media, LLC, part of Springer Nature 2019
}

To our editors, reviewers, and contributors,

The Journal of Neuroimmune Pharmacology (JNIP), the official Journal of the Society on NeuroImmune Pharmacology, is headed into its $14^{\text {th }}$ year. With your help, we have gained substantial momentum in recent years. No doubt our journal clearly occupies an important niche in the fields of neuroscience, immunology and pharmacology linking three seemingly disparate disciplines.

Over the past 13 years, timely reviews, brief reports and cutting-edge primary research papers were published and proved impactful at multiple levels. Publication of these would not be possible without the support of our editorial board and over 1300 volunteer reviewers. Your expertise provided outstanding peer reviews and steered JNIP forward.

JNIP has also added a number of quarterly issues to strengthen our leadership role in publishing timely research. To kick off the 2019 year, Dr. Tricia Burdo led one special the theme issue focused on the "Role of macrophages in HIV persistence during antiretroviral therapy." Other themes include "Defining the role of CRISPR Cas9 in infectious, inflammatory and developmental diseases of the nervous system (Dr. Kalipada Pahan); "Dopaminergic and adrenergic pathways as targets for drug repurposing in neuroimmune networks (Dr. Marco Cosentino); Exosomes in HIV and drugs of abuse (Dr. Santosh Kumar); Exosomes and Drug Delivery (Drs. Nazira El-Hage and Elena Batrakova); and HIV antiretroviral drug-associated toxicities (Dr. Kelly L. Jordan-Sciutto). We invite any of our readers to broaden these and suggest new themes; and we will certainly consider each and every one. We thank all our guest editors for their hard work in recruiting field leaders to participate.

Howard E. Gendelman

hegendel@unmc.edu

1 Department of Pharmacology and Experimental Neuroscience, University of Nebraska Medical Center, 985880 Nebraska Medical Center, Omaha, NE 68198-5880, USA
This past year we also named a new European editor. Dr. Marco Cosentino joins our other senior editors Drs. Raymond Chuen-Chung Chang (Asia and Pacific Rim) and Kalipada Pahan (North America) in strengthening our mission in therapeutics, pathogenesis and immunity for nervous system disorders. We thank Dr. Irena Kadiu for her tenure as our past European editor.

Independent from publishing high quality work, JNIP also believes in training the next generation of scientists; and we have had the privilege of bringing trainees into the peer review process. In 2018-2019, JNIP began a trial for student reviewers. Tiffany A Peterson, Tulane University, and Kristen McLaurin, University of South Carolina, were selected as mentored reviewers from a cadre of strong candidates. We hope this experience has been an engaging and learning time and a win-win for all engaged.

And not to be forgotten, we extend a special thank you to our authors. Your hard work and contributions to JNIP continue to move the field forward.

We look forward to the coming years and yes the best is clearly yet to come.

Howard E. Gendelman, M.D.

Editor-in-Chief

Robin Taylor

Managing Editor

Publisher's Note Springer Nature remains neutral with regard to jurisdictional claims in published maps and institutional affiliations. 